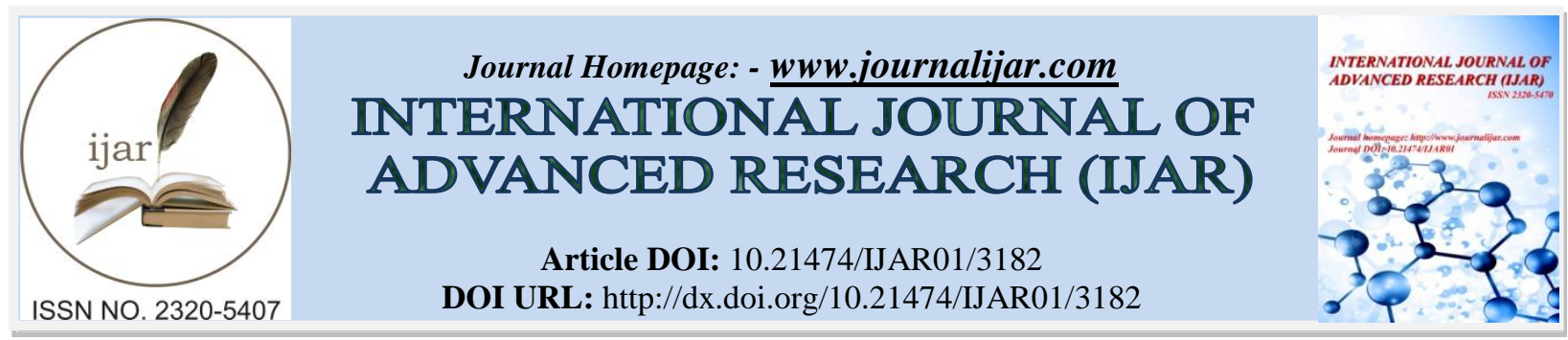

RESEARCH ARTICLE

\title{
DESIGN OF HYBRID CONCENTRATED SOLAR AND WIND POWER PLANT FOR THE AUTONOMY OF ISLANDS.
}

\section{B. Dhivya ${ }^{1}$ and Dr. K. Malarvizhi ${ }^{2}$.}

1. PG Scholar, Department of Electronics and Communication Engineering, Kumaraguru College of Technology Coimbatore, India.

2. Head of the Department, Department of Communication Engineering, Kumaraguru College of Technology, Coimbatore, India.

\section{Manuscript Info}

(.........................

Manuscript History

Received: 12 December 2016

Final Accepted: 04 January 2017

Published: February 2017

Key words:-

Renewable hybrid power plant;

concentrating solar power;

Renewable energy; Vienna

rectifier.

\section{Abstract}

Renewable energy sources can offer isolated communities the chance for employment to regulate their energy use in a manner that best suits their needs. This paper presents the simulation and thermodynamic evaluation of a stand-alone hybrid power plant using renewable energy sources and storage technologies exclusively. Here, the proposed system includes Vienna rectifier for the wind system in order to reduce voltage stress on semi conductor devices and switching losses. The analysis shows that the evaluated hybrid concentrating solar-wind power plant is a reliable alternative for satisfying the fluctuating electricity demand. The output stable and controlled autonomous performance using the complementary character of solar and wind energy, combined with energy storage is verified by simulating using MATLAB Simulink.

Copy Right, IJAR, 2017,. All rights reserved.

\section{Introduction:-}

Generally islands have the most carbon-intensive primary energy supply, because of its strong dependency on oil and lignite. $55 \%$ of the domestic energy demand is met with oil, approximately $99 \%$ of which is imported. For the oil energy needs of the islands alone, the country spends more than 500 million Euro a year, in order to generate electricity at local power plants. The relatively high cost of electricity of isolated areas and non interconnected islands increased the competitiveness and encourages the wider incorporation of renewable energy technologies that may, in other cases, seem economically subaltern to business-as usual energy solutions. With this in mind and accounting for the high potential of the country in renewable sources, it is expected that appropriate energy policies could contribute significantly to the economic recovery of islands.

Today, producing electrical power by renewable sources such as wind, solar and wave are becoming very important since the demand of electrical energy is increasing promptly and the fossil fuel sources are restricted. Among these renewable sources, wind is highly preferred and wind conversion systems technology already plays an important role in power production. Since power is proportional to the cube of wind speed, the location of wind turbine becomes important. Therefore, building offshore wind farm is a good alternative to extract maximum power due to high average wind speed. With this wind speed we have added Concentrated Solar Power (CSP) plant to form the hybrid system. The addition of the CSP system would create a hybrid project that maintains or improves the power output. 
In this paper Vienna rectifier is used in the wind system for Power Factor Correction and to reduce power quality problems. The switching losses, number of MOSFET's are reduced by using Vienna rectifier. The efficiency of the system is improved. The output efficiency and the accuracy of the system is analyzed and verified by simulating the proposed system using MATLAB Simulink.

\section{Related Works:-}

Kolar, J.W.; Ertl, H.; Zach, Franz C., The development of guidelines for the practical application of a new power module (IXYS VUM25-E) realizing a bridge leg of a three-phase/switch/level PWM (VIENNA) rectifier system with low effects on the mains was discussed. The inner circuit structure of the power module was formed by a bidirectional bipolar switch and of two free-wheeling diodes. In the first stage, the switching losses of the power MOSFET and of the free-wheeling diodes are determined by measurement in dependency on the switched current for characteristic values of the junction temperature. The isolated driving stage of the MOSFET was designed for minimum switching losses considering the occurring switching over voltages and the ringing between the parasitic components. The conduction losses of the semiconductor elements are calculated directly via simple analytical approximations of the mean and rms values of the device currents. Based on the proficiency of the dependency of the main loss contributions of the semiconductors of the power module, the operating parameters such as mains voltage, output voltage, heat sink temperature and switching frequency and the maximum allowable mains current amplitude was calculated [1].

R Rajesh, M.; Singh, B., presented the power quality improvement in the midpoint converter based switched reluctance motor (SRM) drive using a Vienna rectifier. A conventional bridge rectifier with midpoint converter based SRM drive yields very high level of harmonics content and low power factor at ac mains. They proposed Vienna rectifier with midpoint converter fed SRM drive that improves the power factor at ac mains with low current harmonics. It also provides constant dc link voltage and balanced capacitor voltages [2].

A. Rajaei, M. Mohamadian, and A. Y. Varjani, presented the improved factors, such as higher efficiency and improved total harmonic distortion by the use of Vienna rectifier as generator-side converter of wind energy conversion system (WECS) consisting a permanent-magnet synchronous generator (PMSG) compared to the traditional back-to-back inverter. The direct torque control (DTC) of the generator in WECS includes fast torque response, insensitivity to PMSG model and associated parameters, elimination of rotor position sensor, and reduced computations. The effects of Vienna rectifier voltage vectors on PMSG torque and stator flux are derived, and DTC of PMSG by the Vienna rectifier is implemented, considering the constraints imposed by the Vienna rectifier [3].

H. Chen and D. C. Aliprantis, discussed about the topology consisting of a squirrel-cage induction machine combined with a Vienna rectifier for a wind energy conversion system. It is energy efficient compared to a traditional six-switch two-level converter. This topology can have higher reliability, due to reduced blocking voltage stress across the semiconductors [4].

C. Qiao and K. M. Smedley, presented about unified constant-frequency integration controller for a three-phase starconnected switch three-level rectifier. It is based on one-cycle control and is simple and reliable. It does not require multipliers to scale the current reference according to the output power level and the input voltage sensor is eliminated. It employs constant switching frequency modulation that is desirable for industrial applications. This controller can be operated on sensing either the inductor currents or the switching currents., The cost is further reduced, if the switching currents are sensed because switching currents are easier to sense comparing with inductor currents [5].

M.A. Barik and H.R. Pota, presented the effects of integration of renewable energy sources (RES) in a microgrid in grid connected and islanded operation. To analyze the complementary feature of renewable energy penetration into microgrid, a fixed speed wind turbine equipped with squirrel cage induction generator (SCIG) and a grid connected solar system with maximum power point tracker (MPPT) are used. They also compared the effect of wind and solar penetration separately as well as jointly [6].

S.H. Madaeni, R. Sioshansi and P. Denholm, estimated the capacity value of concentrating solar power (CSP) plants with thermal energy storage (TES) in the southwestern U.S. Our results show that incorporating TES in CSP plants deliberately increases their capacity value. While CSP plants without TES have capacity values ranging between 
$60 \%$ and $86 \%$ of maximum capacity, plants with TES can have capacity values between $79 \%$ and $92 \%$. They demonstrated the effect of location and configuration on the operation and capacity value of CSP plants [7].

R. Sioshansi and P. Denholm analyzed the potential benefits of locating wind and concentrating solar power (CSP) plants in the southwestern U.S. Using a location in western Texas as a case study, it is manifest that such a deployment strategy can improve the capacity factor of the combined power plant and the associated transmission investment. This was because of two synergies between wind and CSP: 1) the negative interaction between real-time wind and solar resource availability and 2) the need of low-cost high-efficiency thermal energy storage in CSP. The economic tradeoff between transmission and system performance is eminently sensitive to CSP and transmission costs [8].

J. Usaola, discussed about the CSP technology, which will most likely develop in some parts of the world in the near future which has been already exploited in certain countries, such as the USA and Spain, where subsidy policies are granted to support its development. The possibility of storing the received thermal energy and usage of the energy later is an effective constraint. This storage allows CSP plants to smooth the power generation and to schedule it independently of the instantaneous solar resource. These plants may be considered as dispatchable, and can be easily and efficiently integrated to the grid [9].

Keith E. Holbert, presented about the electricity generation using renewable energy, particularly solar power which has been increased considerably in recent years. Solar energy resources in the southwestern U.S. are the best in the world. A significant number of solar thermal generating stations using parabolic concentrators or central receivers are commonly preferred. Concentrating solar power (CSP) plants require condenser cooling, which is provided using water resources. To ensure sustainability of solar-electric facilities in the Southwest, requirements for CSP units to utilize dry cooling may be prudent [10].

Maria Dicorato, Giuseppe Forte, Maria Giovanna Pisani, Enrico De Tuglie, discussed the available technologies for energy production from solar source. Concentrating Solar Power could give a significant contribution to develop a more sustainable energy system. The work is about to investigate a Concentrating Solar-Trough plant, having nominal power equal to $100 \mathrm{KW}$. And exploiting linear parabolic collectors, to produce electric energy by means of Organic Rankine Cycle Turbine. In particular, a model to estimate solar radiation on a sun-tracking surface is preferred, in order to minimize the angle of incidence and thus maximize the incident beam radiation [11].

S. Alekhya, D. Aarti, Raghavender Kulkarni., attempts a heat energy storage for power generation in which a Molten Salt is preferred for Thermal Energy Storage for Concentrating Solar Power systems. In this method numerous large, flat, sun-tracking mirrors, known as heliostats are used which focuses sunlight onto a receiver at the top of a tall tower. A heat-transfer fluid heated in the receiver is used to produce steam, which in turn, is used in a conventional turbine generator to produce electricity. Some power towers use water/steam as the heat-transfer fluid. Solar power tower convert sunshine into clean electricity. The gained thermal energy can be used for molten salt, which saves the energy [12].

\section{Hybrid Generation System:-}

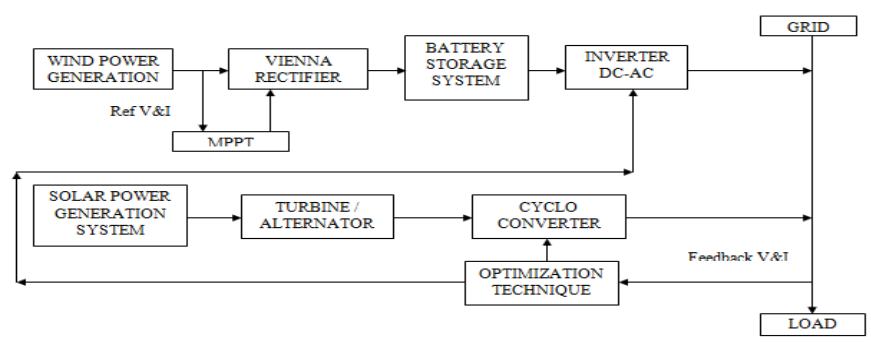

Fig. 1. Block diagram of proposed system

The proposed system block diagram is shown in the Figure 1. Hybrid renewable energy system is used as the input source. In the wind system Vienna rectifier is preferred in order to reduce losses and ripples to improve the Power Factor. Then the battery storage system is to store the energy. By optimization technique the power is injected to the grid on high demand time and for fluctuation compensation. 


\section{A. Concentrating Solar Power plant}

In Concentrating Solar Power (CSP) technique sun's Direct Normal Irradiation (DNI) is concentrated to produce heat of temperature about $400^{\circ} \mathrm{C}$ to $1,000^{\circ} \mathrm{C}$. This heat is then used to generate electricity by the traditional process of steam cycle, or combined cycle, or Stirling engine. Based on the process of collecting and concentrating solar radiation, the CSP can be identified into four major technologies:-

1) Parabolic Trough: Long, curved mirrors pivot is preferred concentrate sunlight onto the tubes filled with a heat transfer fluid, commonly oil or water, whose steam rotates a power- generating turbine. These systems are the mostly used CSP technology and have operated in the United States since the 1980s. Optimal capacity size is 150- $250 \mathrm{MW}$ that is enough to power 44,000 homes, although $80 \mathrm{MW}$ is the largest plant size nowadays. In alternate, one U.S. Company, Sopogy Inc., has created a "Micro CSP" system that uses a scaled- down parabolic system for generation on rooftops.

2) Linear Fresnel Reflectors (LFR): Still in the demonstration stage, LFR systems operates like parabolic trough systems but uses flat mirror strips instead of curved mirrors. Although less efficient than other CSP systems, has cheaper cost of flat mirrors lowers with initial investment cost.

3) Dish/Engine: Mirrored dishes track the sun and concentrates the heat onto a for power generation unit that has a heat- responsive fluid powered engine. Stirling engines, the most common type of engine for this system, do not require the vast water cooling system needed for steam engines because its engine is powered by the expansion- contraction of hydrogen gas as it is heated and cooled. The newest systems have 31.5 percent sun- to- grid energy conversion efficiency, the highest among CSP plants. However, they have a smaller production capacity of $0.003-0.025 \mathrm{MW}$. The first commercial deployment of a dish/Stirling system array is planned for 2010 .

4) Power tower: Fields of flat mirrors concentrates sunlight onto a central receiver which is filled with a heat- transfer fluid, most often molten salt, which can trap thermal energy for long periods. These systems focus heat at higher temperatures than other conventional CSP systems, improving its conversion efficiency. A $20 \mathrm{MW}$ power tower system came online in April 2009 outside Seville, Spain, and the early Solar Two demonstration plant, a 10 MW facility that operated from 1996- 1999 in Barstow, California, had a storage tank which provided three hours of electricity when the sun was not shining.

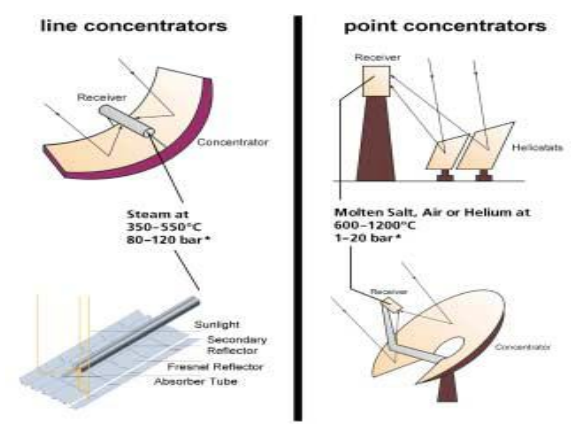

Fig. 2. Technologies for concentrating solar radiation: left side parabolic and linear Fresnel troughs, right side central solar tower receiver and parabolic dish

\section{B. Wind Power Plant:-}

A wind energy conversion system or wind energy harvester is a machine that, powered by the energy of the wind, produces mechanical energy that can be used to directly power machinery to power an electrical generator for making electricity.

\section{1) Schemes for Wind Power Generation:}

Based on the speed and frequency, generally following schemes are identified:

1. Variable Speed Constant Frequency Scheme (VSCF)

2. Variable Speed Constant Frequency with Dual Output(VSCF with DO)

3. Variable Speed Variable Frequency Scheme(VSVF) 


\section{Dual Speed Constant Frequency Scheme (DSCF)}

Among all these schemes the preferred scheme for the proposed system is Variable Speed Variable Frequency Scheme.

\section{2) Variable Speed Variable Frequency Scheme:}

This scheme is suitable for loads that are frequency insensitive such as heating load.

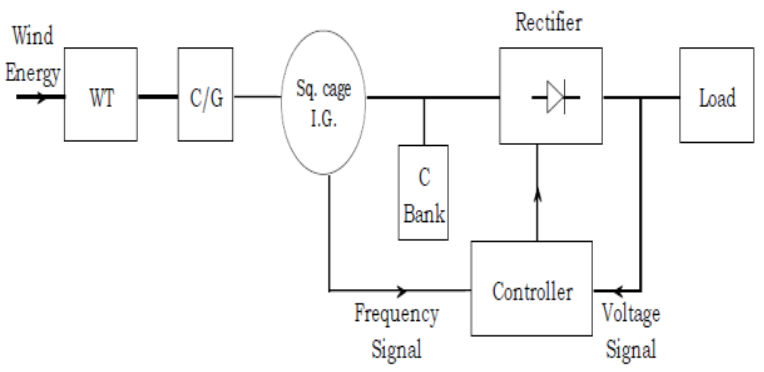

Fig. 3. VSVF Scheme

Depending upon the wind speed, squirrel cage Induction Generator produces power at variable frequency. Such generators are charged by Capacitor-bank. The magnitude and frequency of the generated emf relies on the wind turbine speed, excitation capacitance and load impedance.

If the load demands constant dc voltage, output of generators is converted into D.C using chopper controlled rectifiers. Feedback system can be used to monitor and control to get desired performance.

a) Lower Power Demand on Start: If power is proportional to current-times-voltage, then power needed to excite an AC motor across the line is extremely higher than with an Adjustable Speed AC Drive. This is possible only at start, since the power to run the motor at load would be equal if it were fixed speed or variable speed. The issue is that some distribution systems are at their limit, and demand factors are fixed on industrial customers, which charges them for surges in power that could strip other customers or tax the distribution system during peak periods. These demand factors would not be a typical issue with an Adjustable Speed AC Drive.

b) Controlled Acceleration: An Adjustable Speed AC Drive starts at zero speed and accelerates competently on a customer-adjustable ramp. On the other hand, an AC motor started across the line is a dreadful mechanical shock both for the motor and connected load. This shock will increase the wear and tear on the connected load, and also the AC motor. Some applications, such as bottling lines, cannot be started with motors, but must be started empty to avoid breakage.

c) Reduced Power Line Disturbances: Starting an AC drive across the line, and the consequent demand for sevento-eight times the motor full-load current, places an excessive drain on the distribution system which is connected to the motor. Typically, the supply voltage sags, with the amplitude of the sag and dependent on the size of the motor and the capacity of the distribution system. These voltage distortions can motive sensitive equipment connected on the same distribution system to trip offline due to the low voltage. Items such as computers, sensors, proximity switches, and contactors are voltage sensitive. Adjustable Speed AC Drive reduces this voltage sag, since the motor is started at zero voltage and ramped up.

d) Adjustable Torque Limit: Use of an Adjustable Speed AC Drive can preserve machinery from damage, and protect the process or product An example would be a machine jam. With an AC motor connected, the motor will continue to rotate until the motor's overload device opens An Adjustable Speed AC Drive, can be set to restrict the amount of torque so the AC motor never exceeds this limit.

e) Energy Savings: Centrifugal fan and pump loads operated with an Adjustable Speed AC Drive minimizes energy consumption. Centrifugal fans and pumps follow a variable torque load profile, which has horsepower proportional to the cube of speed and torque varies with proportional to the square of speed. As such, if the speed of the fan is cut in half, the horsepower needed to run the fan at load should be cut by a factor of eight $(1 / 2)^{3}=1 / 8$. Using a fixed 
speed motor would need some type of mechanical throttling device, such as a vane or damper; but the fact remains that the motor would still be operating full load and full speed (full power). Energy savings can be sufficient to pay back the capitalized cost in a matter of a couple of years (or less), depending on the size of the motor.

f) Elimination of Mechanical Drive Components: Using an Adjustable Speed AC Drive can avoid the need for expensive mechanical drive components such as gearboxes. Because the AC Drive can function with an infinite variable speed, it can distribute the low- or high-speed required by the load, without a speed-increasing or reduction devices between the motor and load. This eliminates maintenance costs, as well as reducing floor-space requirements.

\section{Vienna Rectifier:-}

The Vienna rectifier was introduced in 1993 by Prof. Johann W. Kolar. It is a three phase, three levels and three switch rectifier; it is kind of PWM (Pulse Width Modulation) rectifier with controlled output voltage. The topology of the Vienna Rectifier comprising of a boost DC \DC converter with a three-phase diode bridge rectifier. Fig.3 illustrates this rectifier circuit.

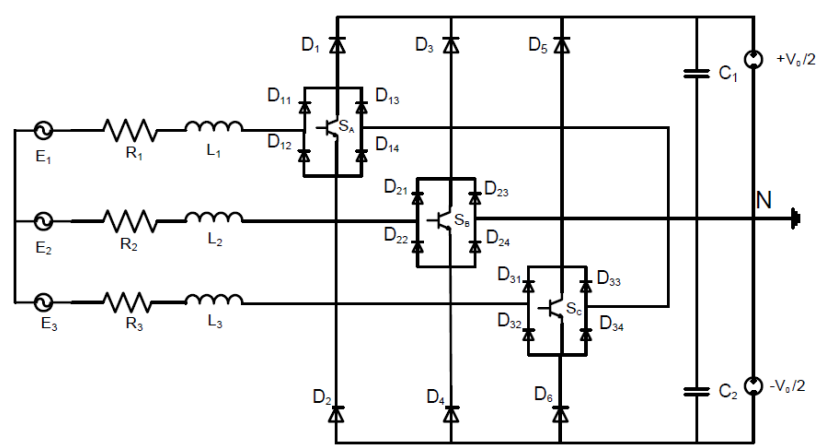

Fig. 4. Vienna rectifier

As Fig. 4, shows the output capacitor is split in two parts with two equal values (C1 and C2). Across each capacitor, two voltage sources $+\mathrm{V}_{0} / 2$ and $-\mathrm{V}_{0} / 2$ exists. Therefore three different voltages $\left(+\mathrm{V}_{0} / 2,0,-\mathrm{V}_{0} / 2\right)$ available here. The DC bus voltage is assumed to be a constant dc voltage and can be connected to a conventional six switch inverter.

The input current for each phase will be defined by the voltage applied across the corresponding inductor $\mathrm{L}_{\mathrm{N}}$. The input voltage of the rectifier is by the switching state and also the input current direction. The input inductors $\left(\mathrm{L}_{\mathrm{N}}\right)$ charge when the switch is on and there is an increase in current in the inductor, and when the switch is off the inductors discharge through the positive or negative diode which depends on the current flow direction. The existence of an input inductor creates a current source at the input while the capacitors create output voltages.

\section{Energy Storage:-}

Wind power turbines have operational constraints over very high and very low speeds. When the power generated exceeds the demand, excess energy can be stored to be used at other times.

- Excess energy can be efficiently stored in storage batteries in the form of chemical energy.

- $\quad$ Excess energy can also be stored in water power storage as mechanical energy. Wind power plant (WPP) along with Hydroelectric power plant (HPP), when the power generated $(\mathrm{Pg})$ exceeds the power demand $\left(\mathrm{P}_{\mathrm{d}}\right)$, helps to partly switch hydro power plant output to Pumping motor (PM) to pump water from an reservoir at the bottom of the dam to main reservoir. 


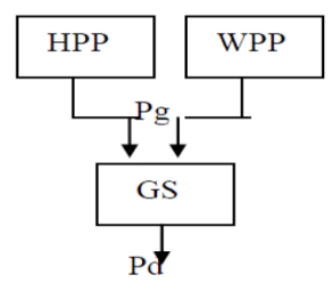

$\mathrm{Pg}=\mathrm{Pd}$

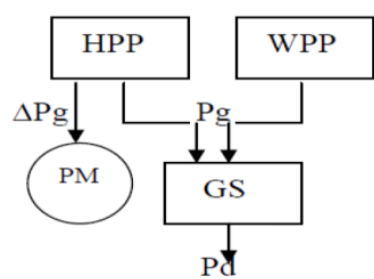

$\mathrm{Pg}>\mathrm{Pd}$

Fig. 5. Energy Storage

\section{Simulation Module:-}

The hybrid power plant proposed in this paper includes a concentrating solar power (CSP) plant including thermal storage with wind energy coupled with electricity storage.

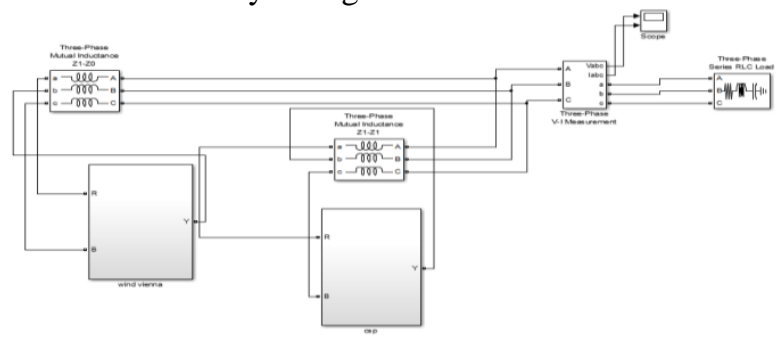

Fig. 6. Simulation Module of the Hybrid System

The simulation module of the proposed system is shown in Fig. 5. Here Wind system and Concentrated Solar Power (CSP) plant is used as the input source for the system. The sub systems are shown below with simulation results.

\section{A. Wind System Simulation Module:-}

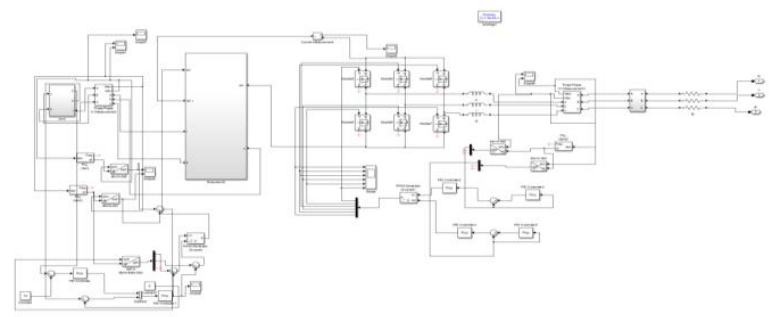

Fig. 7. Simulation Module of Wind System

Fig. 6. shows the Wind system, where the Vienna rectifier is added to the wind system for reduce the switching losses and voltage stress on power semiconductor devices.

Here the maximum power from the wind system is tracked using MPPT tracking. And accordingly the Vienna rectifier is operated. Fig. 7 shows the simulation module of the Vienna rectifier.

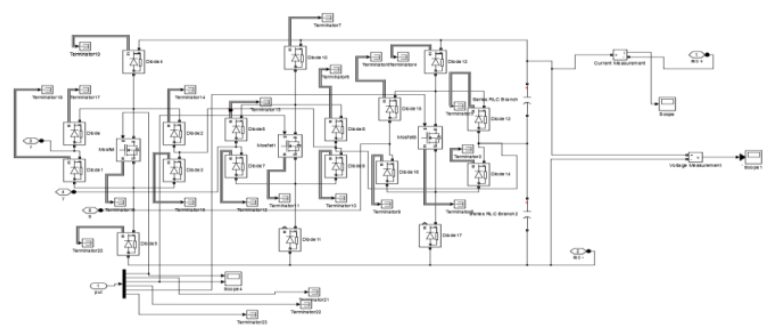

Fig. 8. Simulation Module of Vienna Rectifier 


\section{B. CSP simulation module:-}

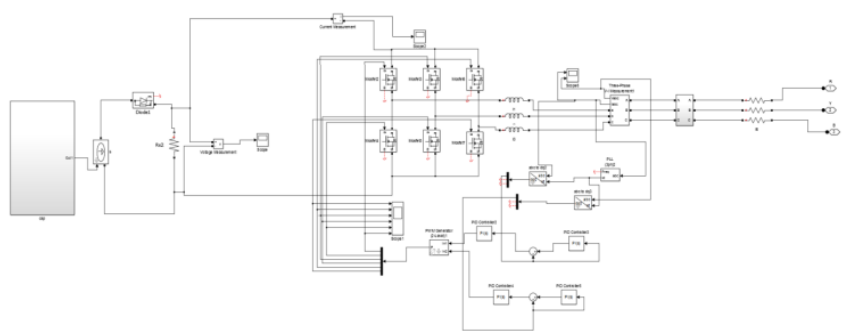

Fig. 9. Simulation Module of Solar Power System

As discussed above this plant works on solar heat power. The heat is transferred to electricity by some processes as mentioned above. The simulation module of the CSP system is shown in Fig. 9.

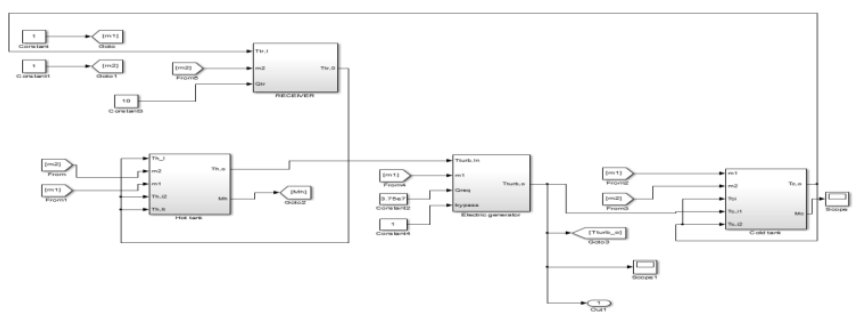

Fig. 10. Simulation Module of CSP

\section{Simulation Results:-}

The simulation module is designed using MATLAB Simulink and the output results are verified. The simulation result waveforms are shown in the below figures.

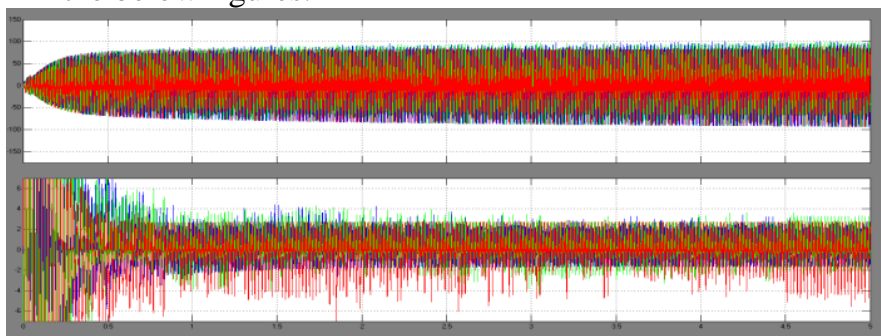

Fig. 11. Wind system output voltage and current waveform

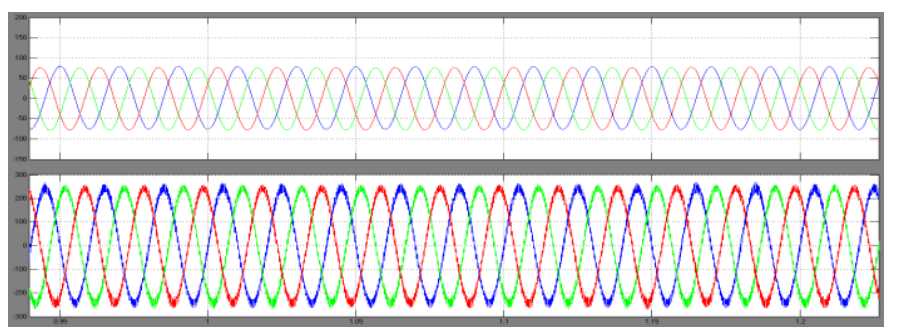

Fig. 12. Output Voltage and current waveform with Vienna rectifier

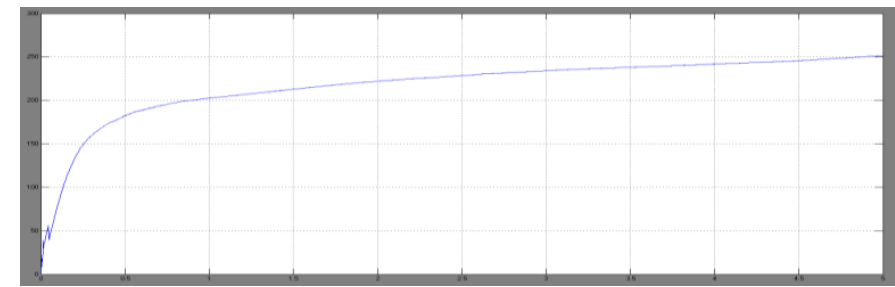

Fig. 13. Output DC voltage waveform 


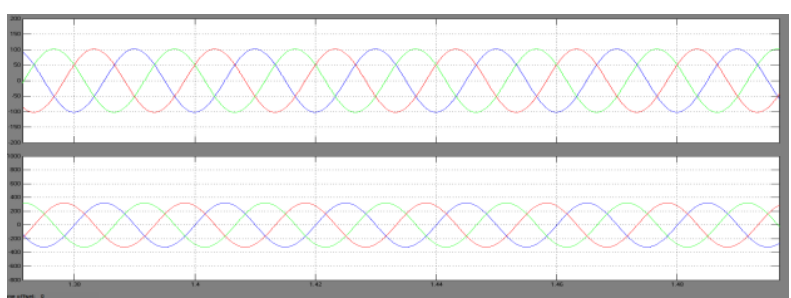

Fig. 14. CSP output voltage and current waveform

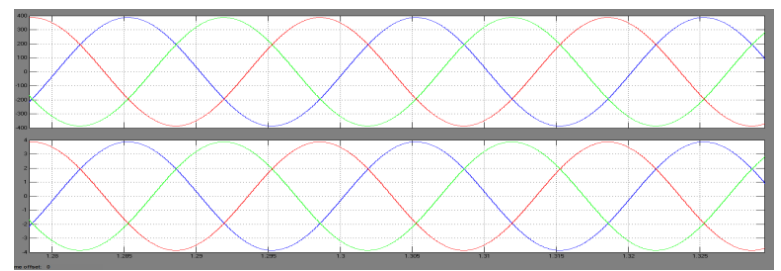

Fig. 15. Output waveform of the proposed system

\section{Conclusion:-}

In this paper the efficiency of the conventional system is improved by including Vienna rectifier in wind system. Here, maximum losses are reduced and power factor is improved. This system is a promising alternative in locations where the extension of the electrical grid is difficult or not economical, where the cost of electricity is high, or where the electricity generation is associated with significant harmful emissions. The efficiency and the stability of the system are verified by simulating the proposed system by using MATLAB Simulink.

\section{References:-}

1. Kolar, J.W.; Ertl, H.; Zach, Franz C., "Design and experimental investigation of a three-phase high power density high efficiency unity power factor PWM (VIENNA) rectifier employing a novel integrated power semiconductor module," in Applied Power Electronics Conference and Exposition, 1996. APEC '96. Conference Proceedings 1996., Eleventh Annual, vol.2, no., pp.514-523 vol.2, 3-7 Mar 1996.

2. R Rajesh, M.; Singh, B., "Power quality improvement in switched reluctance motor drive using Vienna rectifier," in Power India Conference, 2012 IEEE Fifth, vol., no., pp.1-7, 19-22 Dec. 2012.

3. Rajaei, M. Mohamadian, and A. Y. Varjani, "Vienna-Rectifier-Based Direct Torque Control of PMSG for Wind Energy Application,” IEEE Trans. Ind. Electron., vol. 60, no. 7, pp. 2919-2929, Jul. 2013.

4. H. Chen and D. C. Aliprantis, "Analysis of Squirrel-Cage Induction Generator with Vienna Rectifier for Wind Energy Conversion System,” IEEE Trans. Energy Conv., vol. 26, no. 3, pp. 967-975, Sep. 2011.

5. C. Qiao and K. M. Smedley, "Three-Phase Unity-Power-Factor Star-Connected Switch (VIENNA) Rectifier With Unified Constant-Frequency Integration Control," IEEE Trans. Power Electron., vol. 18, no. 4, pp. 952957, Jul. 2003.

6. M.A. Barik and H.R. Pota, "Complementary effect of wind and solar energy sources in a microgrid," Innovative Smart Grid Technologies - Asia (ISGT Asia), 2012 IEEE , pp.1-6, May 21-24, 2012.

7. S.H. Madaeni, R. Sioshansi and P. Denholm, "Estimating the capacity value of concentrating solar power plants with thermal energy storage: A case study of the southwestern United States," in Power Systems, IEEE Transactions on, vol. 28, no. 2, pp. 1205-1215, May 2013.

8. R. Sioshansi and P. Denholm, "Benefits of Collocating Concentrating Solar Power and Wind," in Sustainable Energy, IEEE Transactions on, vol.4, no.4, pp.877,885, 2013.

9. J. Usaola, "Operation of concentrating solar power plants with storage in spot electricity markets," in Renewable Power Generation, IET, vol.6, no.1, pp.59-66, Jan. 2012.

10. Keith E. Holbert, Senior Member, IEEE, Colin J. Haverkamp "Impact of Solar Thermal Power Plants on Water Resources and Electricity Costs in the Southwest".

11. Maria Dicorato, Giuseppe Forte, Maria Giovanna Pisani, Enrico De Tuglie "One-axis tracking optimization of Concentrating Solar Power plant for Electricity production”. Universities Power Engineering Conference (UPEC), 2010 45th International.

12. S. Alekhya, D. Aarti, Raghavender Kulkarni., "Sensible heat storage for power generation", IT Convergence and Security (ICITCS), 2013 International Conference . 